\title{
Use of Morphometric Variables for Differentiating Spanish Hound Breeds
}

\author{
Uso de Variables Morfométricas para la Diferenciación de Razas de Sabueso Español
}

"González, A.; *"Luque, M.; "Rodero, E.; "*González, C.; *Aguilera, R.; ${ }^{* * * *}$ Jiménez, J.; ${ }^{* * * *}$ Sepúlveda, N; ${ }^{* * * *}$ Bravo, S. \& *Herrera, M.

GONZÁlEZ, A.; LUQUE, M.; RODERO, E.; GONZÁLEZ, C.; AGUILERA, R.; JIMÉNEZ, J.; SEPÚLVEDA, N.; BRAVO, S. \& HERRERA, M. Use of morphometric variables for differentiating Spanish hound breeds. Int. J. Morphol., 29(4):1248-1255, 2011.

SUMMARY: The term Podencos refers to a group of dog breeds from Spain and classification in Group 5 of dog breeds by the Fédération Cynologique Internationale (FCI). The aim of this study was to compare traits morphometric breeds of Podencos; Canario, Ibecenco, Andaluz (small, medium and large) and Orito. Ten morphometric variables were measured in 385 animals ( 245 females and 140 males), head length, muzzle length, height at withers, rump height, body length, head width, rump width, chest depth, chest girth and the shin circumference. Morphostructural variables were more homogeneous in the Podenco Ibicenco and the Podengo Canario, because for many years there were gradually distinctive trait standards for each breed. The discriminate analysis indicated morphostructural differences between all breeds, as reflected in the significant Mahalanobis distance, and confirmed that the hound Orito may be accepted as a different dog population.

KEY WORDS: Morphometric; Dog breed; Hound; Multivariate.

\section{INTRODUCTION}

The Podenco is an ancient hunting dog. It is slender and agile, with a deep chest, tucked-up abdomen and erect ears. The Podenco breeds are mainly used for hunting, especially rabbits, although they are also successfully used in hunting larger game, since they are nimble and hardy.

The Spanish Royal Canine Society accepts four breeds belonging to Group 5: the Podenco Canario, the Podenco Ibicenco, the Podenco Andaluz and the Maneto; although only the first two are recognized by the FCI, under the registration numbers 329 and 89, respectively. A further, as yet unrecognized, breed known as Orito because of its golden coat colour is also raised in the same geographical area as the Podenco Andaluz. The Podenco Canario, used primarily for rabbit hunting, is a tracker dog, which should not bark whilst scenting. Height at withers ranges from 55 to $64 \mathrm{~cm}$ in males and from 53 to $60 \mathrm{~cm}$ in females. The Podenco Ibicenco is used mainly for rabbit coursing. Height at withers lies in the range $66-72 \mathrm{~cm}$ for males and $60-67$ $\mathrm{cm}$ for females.
There are three recognized sizes of Podenco Andaluz: small (males 35-42 cm, females 32-41 cm), medium (males $43-53 \mathrm{~cm}$, females $42-52 \mathrm{~cm}$ ) and large (males 54$64 \mathrm{~cm}$, females $53-61 \mathrm{~cm}$ ). They are generally used for hunting rabbits and boar, although the larger dogs are also used in wild fowling.

The Orito hound is also used mainly for hunting a number of different species. It is a tough breed, able to work long hours and adapt to all types of terrain under adverse weather conditions. Height at withers is estimated at around $40 \mathrm{~cm}$ in males, and somewhat less in females.

One aim of this research was to determine the extent to which the Orito hound differed from the three other Podenco breeds, since prior to characterization it was deemed essential to establish whether this was in fact a new breed or a variety of an existing breed. The method used here has been applied to goat breeds (Herrera et al., 1996). In general terms, the examination of morphometric variables using

\footnotetext{
* Departamento de Producción Animal, Campus de Rabanales, Universidad de Córdoba, Córdoba, España.

** Servicios Técnicos FEAGAS, Madrid, España.

**** Asociación Nacional del Podenco Orito Español (ANPOE), Málaga, España

${ }^{* * * * *}$ Facultad de Ciencias Agropecuarias y Forestales, Universidad de La Frontera, Temuco, Chile.
} 
discriminate analysis techniques (simple, stepwise, cluster and canonical) has enabled the differentiation of breeds and varieties of various domestic species (Herrera et al.; Capote et al., 1998; Crepaldi et al.; 2001; Macciotta et al., 2002; Rodero et al., 2003; Lanari et al., 2003; Zaitoun et al., 2005; Luque et al., 2005; Dossa et al., 2007; Marrube et al., 2007; Vargas et al., 2007; Traoré et al., 2008a; Traoré et al., 2008b).

\section{MATERIAL AND METHOD}

Sample. A total of 10 morphometric variables were measured following Herrera et al., in 385 dogs, of which 245 were females (F) and 140 males (M), of the following breeds; small Podenco Andaluz (11 F, 3 M), medium sized Podenco Andaluz (67 F, 24 M), large Podenco Andaluz (16 F, 12 M), Podenco Ibicenco (36 F, 31 M), Podenco Canario (40 F and $24 \mathrm{M}$ ) and Podenco Orito (75 F, $46 \mathrm{M}$ ).

Animals were drawn from the Canary Islands (Podenco Canario), the Balearic Islands (Podenco Ibicenco) and Andalusia (Podenco Andaluz, all three sizes); all study animals were registered in the appropriate breed book. The Orito hounds were from packs raised in the Andalusian town of Archidona (Málaga) and identified as Orito by the breeders, since there is no breed book for this group.

The following measurements were obtained using a measuring stick, callipers and a tape measure as appropriate (Fig. 1): distance measurements (head length, muzzle length, height at withers, height at rump and body length), width measurements (head width, rump width and chest depth) and perimeters (chest girth and shin circumference).

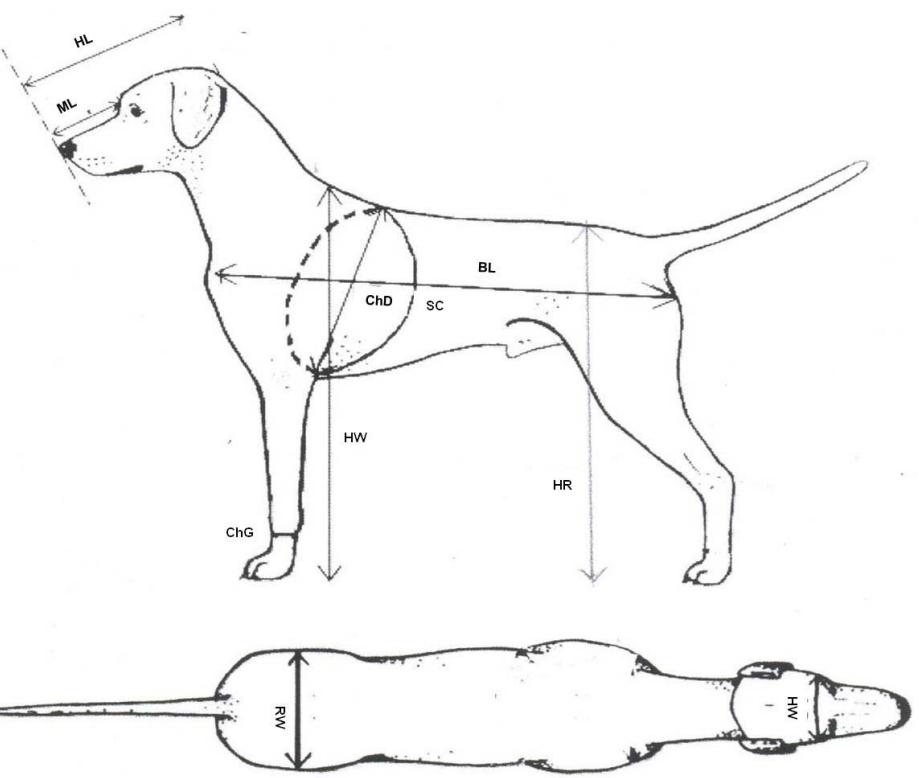

Fig. 1. Morphometric variables and reference points measurements in hounds. Head length (HL), muzzle length (ML), height at withers (HW), height at rump (HR), body length (BL), head width (HW), rump width (RW), chest depth (ChD), chest girth (ChG), shin circumference (SC).
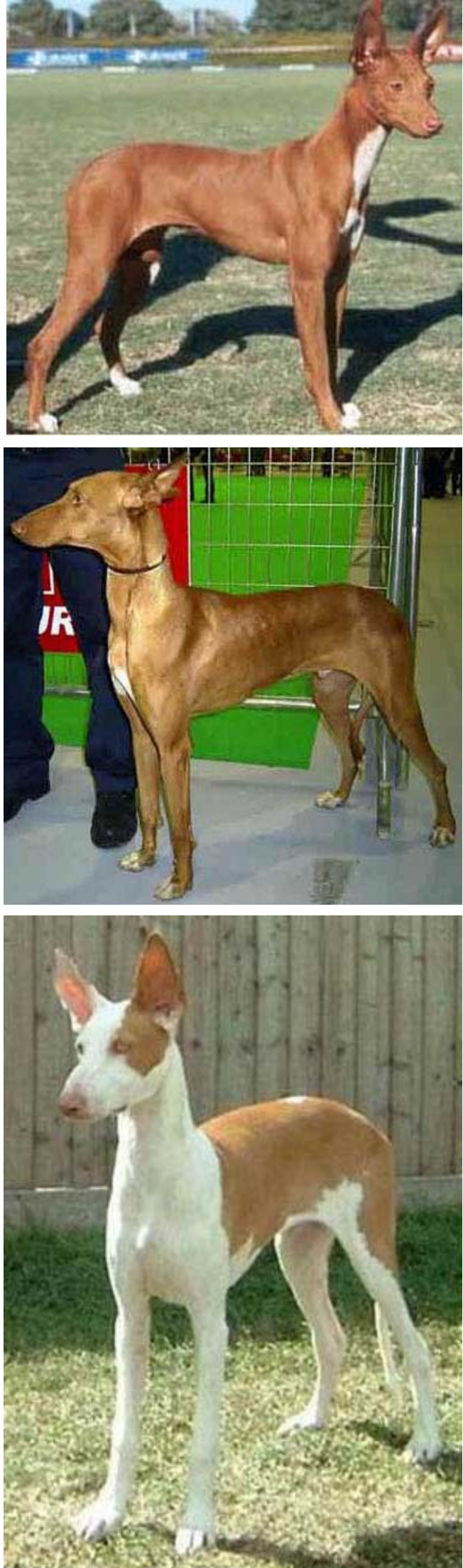
Statistical analysis. Morphostructural characterization was based on the mean and standard deviation of the 10 variables studied. Subpopulation variability was estimated using coefficients of variation, which enabled the morphostructural variability of study animals to be tested in order to establish the degree of heterogeneity/homogeneity.

Discriminant analysis identified those variables most influencing differentiation of breeds and intra-breed varieties. Breeds and varieties were grouped using canonical procedures (plots) and Mahalanobis distances (cluster trees). The ability of this procedure to assign each animal to its breed or variety was calculated in terms of the percentage of correct classification. Statistical analysis was carried out using the statistical software package for Windows 7.0.

\section{RESULTS}

Descriptive statistic for morphometric variables. Canine breed standards include a number of quantitative traits which provide a basis for characterization, the major traits being height at withers and chin circumference; however, to determine similarities and differences between Podenco breeds, a larger number of variables are required. Descriptive statistics for the 10 variables used here are shown in Tables I and II.

Marked differences were observed in morphometric variables. The largest breed was the Podenco Ibicenco, and the smallest the small Podenco Andaluz; the Orito hounds

Table I. Descriptive statistic for morphometric variables in female Podenco hounds.

\begin{tabular}{|c|c|c|c|c|c|c|c|c|c|c|c|c|}
\hline \multirow{2}{*}{ Variables } & \multicolumn{2}{|c|}{ Podenco Canario } & \multicolumn{2}{|c|}{ Podenco Ibicenco } & \multicolumn{2}{|c|}{ Podenco Orito } & \multicolumn{2}{|c|}{$\begin{array}{c}\text { Podenco Andaluz } \\
\text { large }\end{array}$} & \multicolumn{2}{|c|}{$\begin{array}{c}\text { Podenco Andaluz } \\
\text { medium }\end{array}$} & \multicolumn{2}{|c|}{$\begin{array}{c}\text { Podenco } \\
\text { Andaluz small }\end{array}$} \\
\hline & $\mathbf{X} \pm \mathbf{E S}$ & $\mathrm{CV}$ & $\mathbf{X} \pm \mathbf{E S}$ & $\mathrm{CV}$ & $\mathbf{X} \pm \mathbf{E S}$ & CV & $\mathrm{X} \pm \mathrm{ES}$ & $\mathrm{CV}$ & $\mathbf{X} \pm \mathbf{E S}$ & $\mathrm{CV}$ & $\mathrm{X} \pm \mathrm{ES}$ & $\mathrm{CV}$ \\
\hline Height at Whiters & $60.6 \pm 0.5$ & 4.8 & $67.9 \pm 0.5$ & 4.7 & $44.9 \pm 0.5$ & 9.9 & $57.2+0.8$ & 5.3 & $45.4 \pm 0.5$ & 8.2 & $39.6 \pm 1.2$ & 10.4 \\
\hline Height at Rump & $60.4 \pm 0.6$ & 6.1 & $66.8 \pm 0.5$ & 4.1 & $44.7 \pm 0.5$ & 10.4 & $56.6 \pm 0.9$ & 6.4 & $45.4 \pm 0.4$ & 7.9 & $39.5 \pm 1.0$ & 8.7 \\
\hline Body length & $59.3 \pm 0.7$ & 7.2 & $65.2 \pm 0.5$ & 4.9 & $44.3 \pm 0.6$ & 11.0 & $53.8 \pm 1.0$ & 7.5 & $42.2 \pm 0.5$ & 10.2 & $36.8 \pm 1.4$ & 12.2 \\
\hline Chest depth & $22.0 \pm 0.3$ & 10.0 & $23.3 \pm 0.3$ & 6.6 & $16.8 \pm 0.3$ & 14.0 & $20.1 \pm 0.9$ & 17.1 & $15.1 \pm 0.2$ & 11.7 & $13.1 \pm .5$ & 13.4 \\
\hline Head length & $22.0 \pm 0.2$ & 6.0 & 22. & 5.5 & $16.8=$ & 7.9 & $20.4 \pm 0.4$ & 7.2 & $16.5 \pm 0.2$ & 11.5 & $14.6 \pm 0.3$ & 7.8 \\
\hline Muzzle length & $10.0 \pm 0.1$ & 7.5 & $10.6 \pm 0.2$ & 9.9 & $9.0 \pm 0.1$ & 11.5 & $10.1 \pm 0.2$ & 8.9 & $7.6 \pm 0.1$ & 13.7 & $6.5 \pm 0.3$ & 12.7 \\
\hline Head width & $10.1 \pm 0.1$ & 4.4 & $9.9 \pm 0.2$ & 9.5 & $8.6 \pm 0.1$ & 8.7 & $9.6 \pm 0.3$ & 10.8 & $7.9-$ & 9.2 & $7.3 \pm 0.2$ & 9.2 \\
\hline Rump width & $7.4 \pm 0.2$ & 19.3 & $10.2 \pm 0.4$ & 23.2 & $8.3 \pm 0.2$ & 17.1 & $10.7 \pm 0.4$ & 13.2 & $8.9 \pm 0.2$ & 14.2 & $8.2 \pm 0.4$ & 16.6 \\
\hline Shin circumference & $63.0 \pm 0.6$ & 6.12 & $63.9 \pm 0.6$ & 5.4 & $51.3 \pm 0.7$ & 11.4 & $61.1 \pm 1.9$ & 12.9 & $49.0 \pm 0.8$ & 13.6 & $43.7 \pm 1.3$ & 9.5 \\
\hline Chest girth & $10.0 \pm 0.1$ & 7.3 & $10.3 \pm 0.2$ & 10.5 & $8.8 \pm 0.1$ & 11.9 & $10.2+0.4$ & 15.9 & $8.0 \pm 0.2$ & 15.4 & $7.1 \pm 0.3$ & 15.7 \\
\hline
\end{tabular}

Table II. Descriptive statistics for morphometric variables in male Podenco hounds.

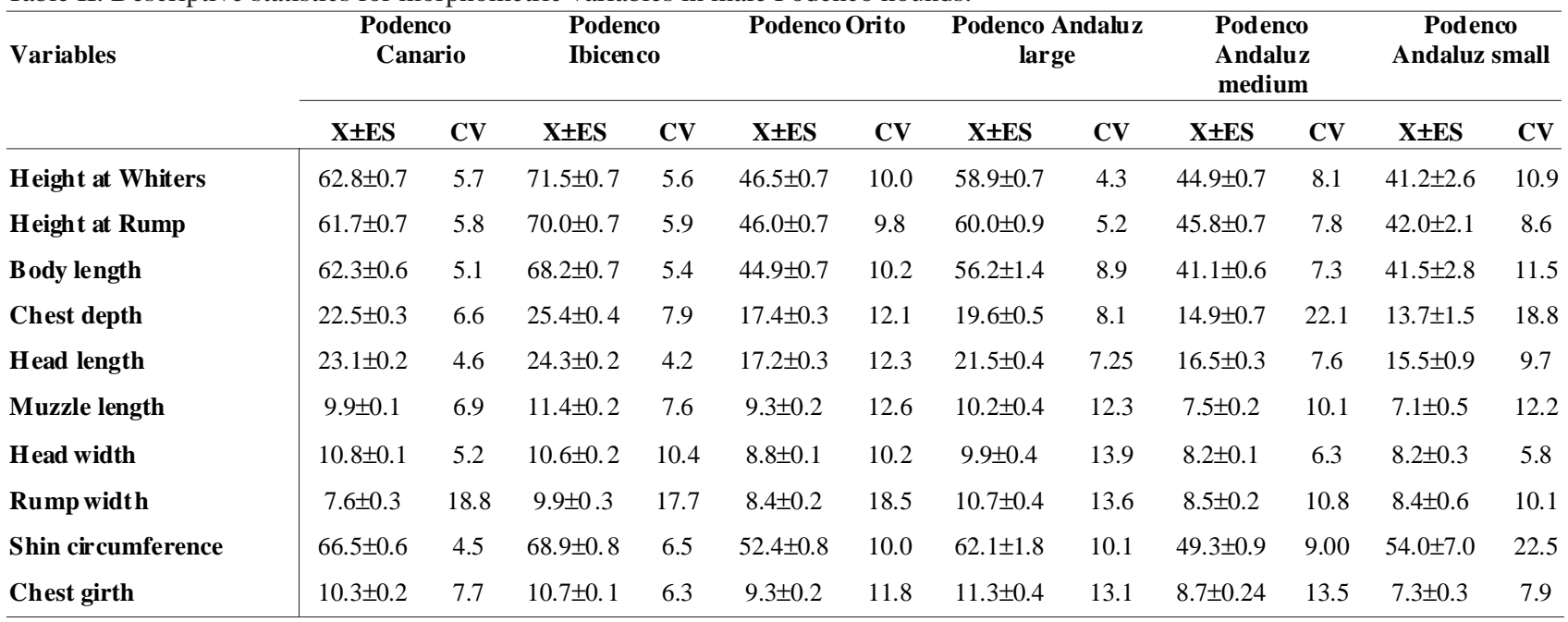


(both sexes) displayed morphometric traits similar to those of the small Podenco Andaluz.

The variables with the lowest coefficients of variation were: height at withers, head length and head width in females, and height at rump, chest girth and height at withers in males. The greatest variability was found for rump width in both sexes.

Causes of variation: principal factor analysis. Principal factor analysis was based on results for all six breeds and varieties in females; for males, data for the small Po- denco Andaluz was not used due to the small number of dogs in the sample.

Two factors (1 and 2) accounted for between 57\% and $78 \%$ of total variance in females, and for between $59 \%$ and $75 \%$ in males (Tables III and IV).

The influence of Factor 1 was significant for height at withers, height at rump, body length and rump width, explaining between $39 \%$ and $64 \%$ of variance in females and between $41 \%$ and $59 \%$ of variance in males, while Factor 2 accounted for between $11 \%$ and $22 \%$ of variance in females and between $13 \%$ and $29 \%$ in males.

Table III. Principal factor in female Podenco hounds.

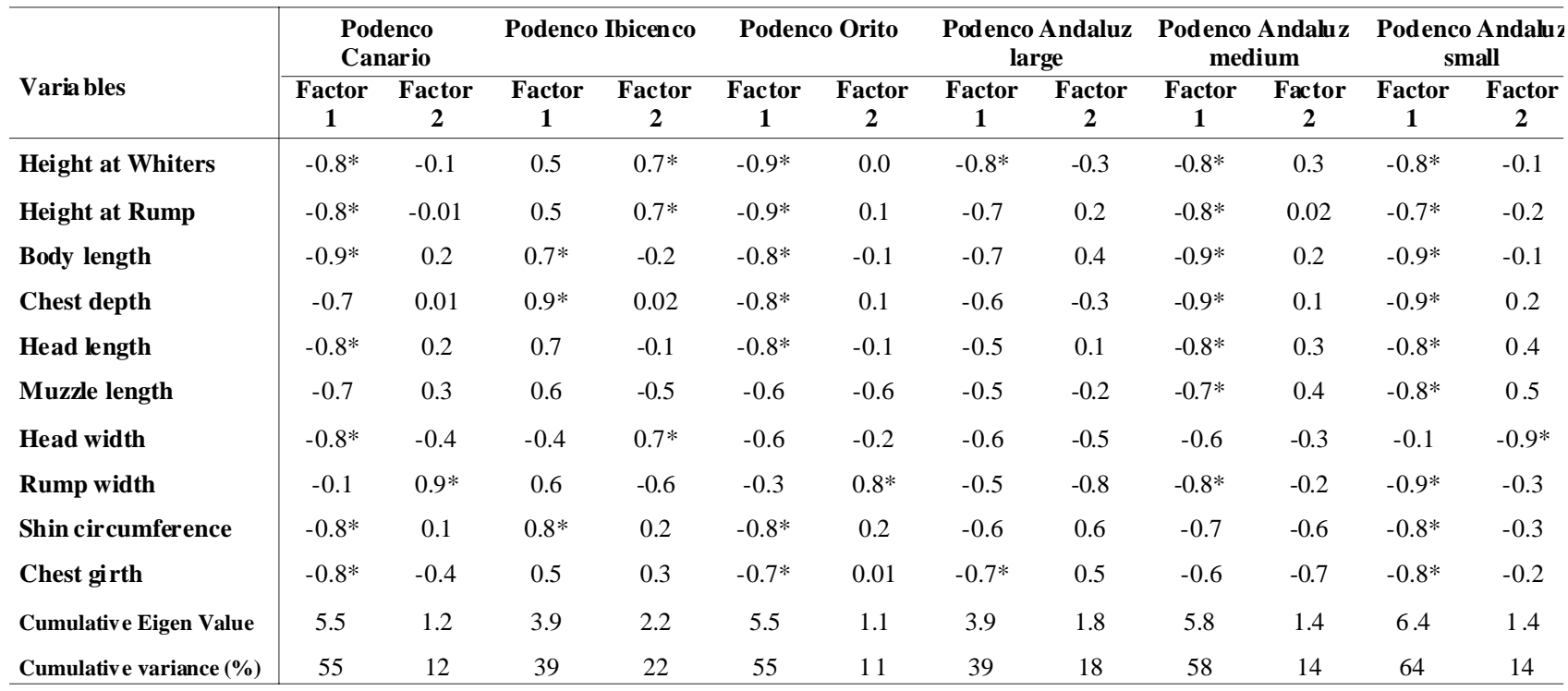

Table IV. Principal factor in male Podenco hounds.

\begin{tabular}{|c|c|c|c|c|c|c|c|c|c|c|}
\hline \multirow{2}{*}{ Variables } & \multicolumn{2}{|c|}{ Podenco Canario } & \multicolumn{2}{|c|}{ Podenco Ibicenco } & \multicolumn{2}{|c|}{ Podenco Orito } & \multicolumn{2}{|c|}{$\begin{array}{c}\text { Podenco Andaluz } \\
\text { Large }\end{array}$} & \multicolumn{2}{|c|}{$\begin{array}{c}\text { Podenco Andaluz } \\
\text { medium }\end{array}$} \\
\hline & Factor 1 & Factor 2 & Factor 1 & Factor 2 & Factor 1 & Factor 2 & Factor 1 & Factor 2 & Factor 1 & Factor 2 \\
\hline Height at Whiters & $-0.8^{*}$ & -0.1 & $-0.9^{*}$ & 0.1 & $-0.9 *$ & -0.2 & -0.7 & 0.1 & $-0.8^{*}$ & -0.1 \\
\hline Height at Rump & $-0.8^{*}$ & -0.1 & $-0.8^{*}$ & 0.1 & $-0.8^{*}$ & -0.1 & $-0.8^{*}$ & 0.37 & -0.6 & 0.3 \\
\hline Body length & $-0.7^{*}$ & 0.3 & -0.3 & -0.7 & $-0.8^{*}$ & 0.1 & $-0.7^{*}$ & 0.2 & $-0.7^{*}$ & -0.5 \\
\hline Chest depth & -0.7 & -0.1 & -0.2 & $-0.8^{*}$ & $-0.7^{*}$ & 0.3 & $-0.8^{*}$ & -0.01 & -0.5 & -0.1 \\
\hline Head length & $-0.8^{*}$ & 0.1 & -0.7 & -0.4 & $-0.7^{*}$ & -0.1 & $-0.8^{*}$ & 0.01 & $-0.8^{*}$ & -0.3 \\
\hline Muzzle length & -0.5 & -0.6 & 0.5 & $-0.8^{*}$ & -0.7 & -0.6 & $-0.9^{*}$ & -0.3 & -0.5 & -0.7 \\
\hline Head width & -0.8 & 0.2 & $-0.8^{*}$ & 0.4 & -0.7 & 0.03 & $-0.8^{*}$ & -0.4 & -0.2 & 0.6 \\
\hline Rump width & -0.3 & -0.5 & 0.4 & $-0.8^{*}$ & -0.3 & $0.9^{*}$ & -0.6 & $-0.8^{*}$ & $-0.8^{*}$ & -0.01 \\
\hline Shin circumference & $-0.7 *$ & -0.3 & -0.6 & -0.3 & $-0.8^{*}$ & -0.04 & $-0.9^{*}$ & 0.2 & $-0.7^{*}$ & 0.5 \\
\hline Chest girth & -0.5 & $0.7 *$ & -0.6 & -0.5 & $-0.8^{*}$ & 0.2 & -0.6 & $0.8^{*}$ & -0.6 & 0.6 \\
\hline Cumulative Eigen Value & 4.6 & 1.3 & 4.1 & 2.9 & 5.3 & 1.3 & 5.9 & 1.6 & 4.2 & 1.8 \\
\hline Cumulative variance (\%) & 46 & 13 & 41 & 29 & 53 & 13 & 59 & 16 & 42 & 18 \\
\hline
\end{tabular}


Table V. Mahalanobis distances for male and female Podenco hounds.

\begin{tabular}{|c|c|c|c|c|c|c|}
\hline Males & $\begin{array}{l}\text { Podenco } \\
\text { Canario }\end{array}$ & $\begin{array}{l}\text { Podenco } \\
\text { Ibicenco }\end{array}$ & $\begin{array}{l}\text { Podenco } \\
\text { Orit o }\end{array}$ & $\begin{array}{c}\text { Podenco } \\
\text { Andaluz large }\end{array}$ & $\begin{array}{l}\text { Podenco } \\
\text { Andaluz } \\
\text { medium }\end{array}$ & $\begin{array}{c}\text { Podenco } \\
\text { Andaluz } \\
\text { small }\end{array}$ \\
\hline Podenco Canario & & $11.1 * * *$ & $31.6^{* * *}$ & $14.4^{* * *}$ & $32.2 * * *$ & $49.5 * * *$ \\
\hline Podenco Ibicenco & $11.0 * * *$ & & $46.2 * * *$ & $14.9 * * *$ & $42.8 * * *$ & $64.6 * * *$ \\
\hline Podenco Orito & $39.8 * * *$ & $64.3 * * *$ & & $13.1 * * *$ & $5.4 * * *$ & $9.8 * * *$ \\
\hline Podenco Andaluz large & $19.5 * * *$ & $27.3 * * *$ & $18.2 * * *$ & & $13.2 * * *$ & $27.9 * * *$ \\
\hline Podenco Andaluz medium & $47.8 * * *$ & $75.7 * * *$ & $6.2 * * *$ & $20.6 * * *$ & & $2.8 * *$ \\
\hline Podenco Andaluz samll & $50.5 * * *$ & $85.3 * * *$ & $9.8 \mathrm{~ns}$ & $31.6 * * *$ & $5.1 \mathrm{~ns}$ & \\
\hline
\end{tabular}

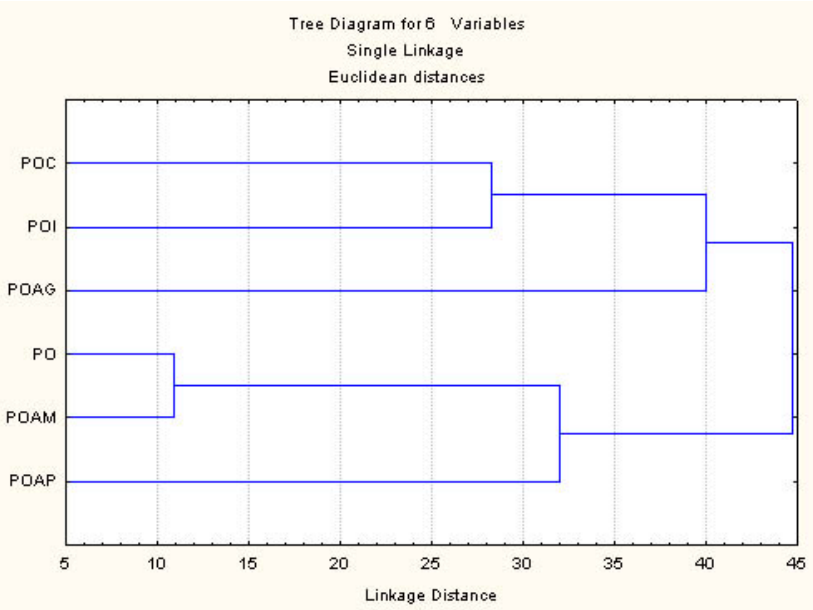

Fig. 2. Cluster tree for female Podenco hounds. POC: Podenco Canario; POI: Podenco Ibicenco; PO: Podenco Orito; POAG: Podenco Andaluz large size; POAM: Podenco Andaluz medium size; POAP: Podenco Andaluz small size.

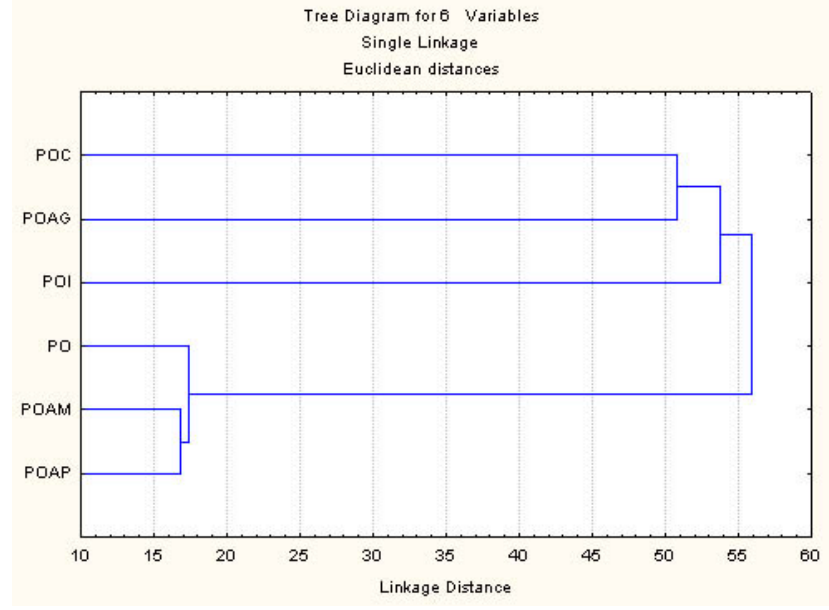

Fig. 3. Cluster tree for male Podenco hounds. POC: Podenco Canario; POI: Podenco Ibicenco; PO: Podenco Orito; POAG: Podenco Andaluz large size; POAM: Podenco Andaluz medium size; POAP: Podenco Andaluz small size.

Table VI. Classification matrix for female Podenco hounds.

\begin{tabular}{|c|c|c|c|c|c|c|c|}
\hline B reeds & Percent & $\begin{array}{l}\text { Podenco } \\
\text { Canario }\end{array}$ & $\begin{array}{l}\text { Podenco } \\
\text { Ibicenco }\end{array}$ & $\begin{array}{c}\text { Podenco } \\
\text { Orito }\end{array}$ & $\begin{array}{l}\text { Podenco } \\
\text { Andaluz } \\
\text { large size }\end{array}$ & $\begin{array}{c}\text { Podenco } \\
\text { Andaluz of } \\
\text { medium } \\
\text { size }\end{array}$ & $\begin{array}{r}\text { Podenco } \\
\text { Andaluz } \\
\text { small size }\end{array}$ \\
\hline Podenco Canario & 97.50 & 39 & 0 & 0 & 1 & 0 & 0 \\
\hline Podenco Ibicenco & 86.11 & 5 & 31 & 0 & 0 & 0 & 0 \\
\hline Podenco Orito & 82.67 & 0 & 0 & 62 & 1 & 12 & 0 \\
\hline Podenco Andal uz large size & 81.25 & 1 & 0 & 0 & 13 & 2 & 0 \\
\hline Podenco Andal uz medium size & 86.36 & 0 & 0 & 5 & 0 & 57 & 4 \\
\hline Podenco Andaluz small size & 27.27 & 0 & 0 & 0 & 0 & 8 & 3 \\
\hline
\end{tabular}

Euclideans distances. Mahalanobis distances used to detect morphometrics differences between breeds (Table V) all proved highly significant $(\mathrm{p} \leq 0,05)$, except for distances between small male Podenco Andaluz, medium-sized Podenco Andaluz and Orito hounds.
For males and females, the greatest distances were between the Podenco Canario and the small Podenco Andaluz, while the shortest distances were between the medium sized and small Podenco Andaluz (both sexes). The results shown in Table $\mathrm{V}$ were represented graphically 
Table VII. Classification matrix for male Podenco hounds.

\begin{tabular}{|c|c|c|c|c|c|c|c|}
\hline B reeds & Percent & $\begin{array}{l}\text { Podenco } \\
\text { Canario }\end{array}$ & $\begin{array}{l}\text { Podenco } \\
\text { Ibicenco }\end{array}$ & $\begin{array}{c}\text { Podenco } \\
\text { Orito }\end{array}$ & $\begin{array}{c}\text { Podenco } \\
\text { Andaluz } \\
\text { large size }\end{array}$ & $\begin{array}{c}\text { Podenco } \\
\text { Andaluz } \\
\text { medium } \\
\text { size }\end{array}$ & $\begin{array}{r}\text { Podenco } \\
\text { Andaluz } \\
\text { small size }\end{array}$ \\
\hline Podenco Canario & 95.83 & 23 & 1 & 0 & 0 & 0 & 0 \\
\hline Podenco Ibicenco & 96.77 & 1 & 30 & 0 & 0 & 0 & 0 \\
\hline Podenco Orito & 91.11 & 0 & 0 & 41 & 0 & 4 & 0 \\
\hline Podenco Andaluz large size & 100.00 & 0 & 0 & 0 & 12 & 0 & 0 \\
\hline Podenco Andal uz medium size & 86.96 & 0 & 0 & 2 & 0 & 20 & 1 \\
\hline Podenco Andal uz small size & 50.00 & 0 & 0 & 1 & 0 & 0 & 1 \\
\hline
\end{tabular}

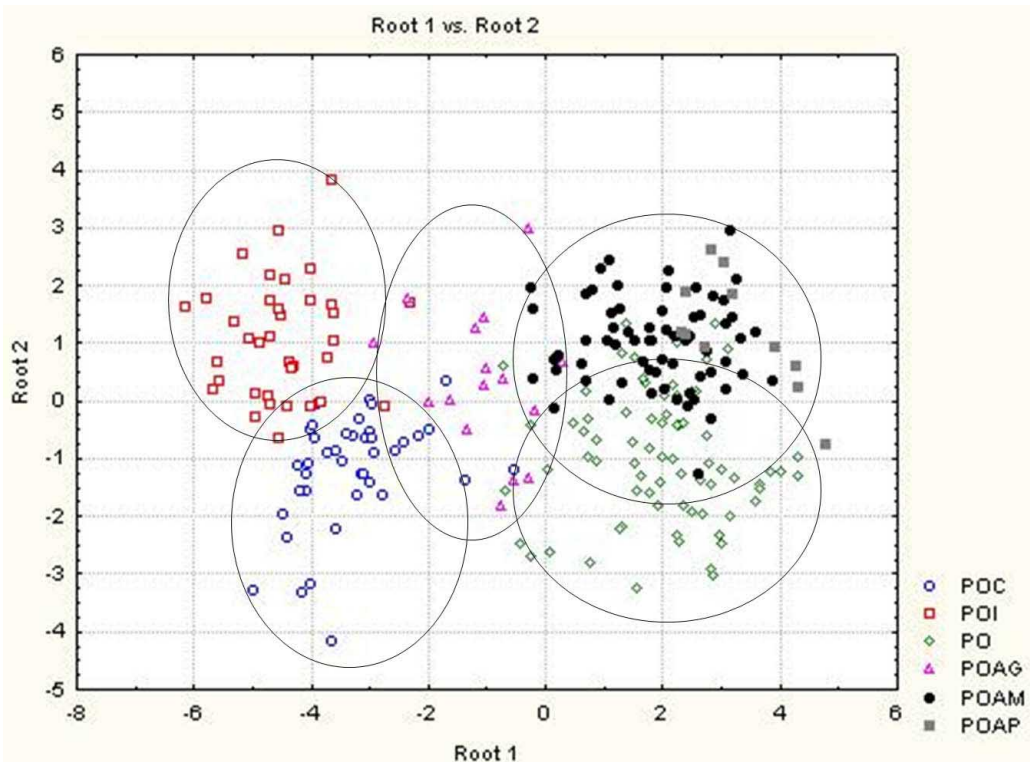

Fig. 4. Plot for females Podenco hounds. POC: Podenco Canario; POI: Podenco Ibicenco; PO: Podenco Orito; POAG: Podenco Andaluz large size; POAM: Podenco Andaluz medium size; POAP: Podenco Andaluz small size.

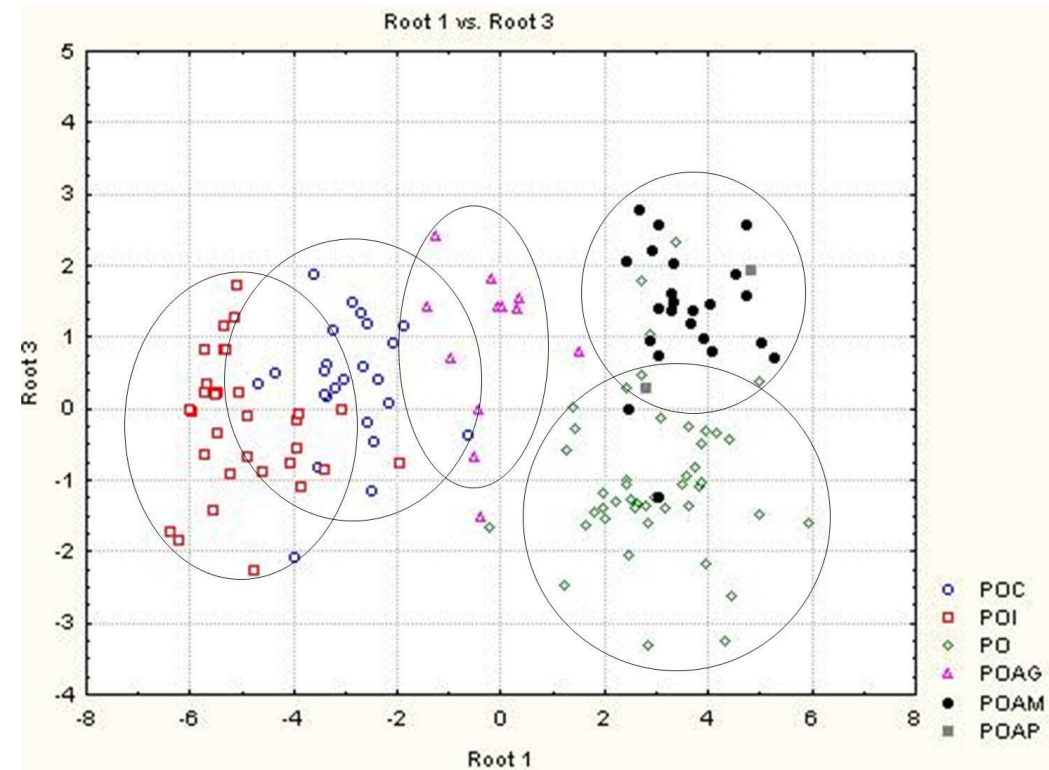

by cluster trees for males and females (Figs. 2 and 3$)$.

For both sexes, the clusters furthest apart were the Podenco Canario and the small Podenco Andaluz, whilst the medium-sized Podenco Andaluz and Orito hounds were morphometrically closer to each other.

Assignment of individual to breeds or varieties. The classification matrices in Tables VI and VII reveal a high rate of correct classification to breed for both sexes, except for the small Podenco Andaluz, where only $27 \%$ of females and $50 \%$ of males were correctly classified.

Correct classification rates were higher for Orito males than females; 41 males were classified as Oritos whilst two were misclassified as medium sized Podenco Andaluz and one as small Podenco Andaluz. Sixty-two females were correctly classified as Oritos, but 5 were misclassified as medium sized Podenco Andaluz.

The plots of canonical coefficients (Figs. 4 and 5) highlight the clear spatial separation of breeds, with the exception again - of the small and medium-sized Podenco Andaluz.

Fig. 5. Plot for male Podenco hounds. POC: Podenco Canario; POI: Podenco Ibicenco; PO: Podenco Orito; POAG: Podenco Andaluz large size; POAM: Podenco Andaluz medium size; POAP: Podenco Andaluz small size. 


\section{DISCUSSION}

In the early twentieth century, a breed was defined as: a group of individuals sharing certain distinctive and transmissible traits, thus suggesting that each breed possesses certain traits distinguishing them from other breeds. A similar underlying approach is found in Cavalli-Sforza (2000), who defines race as: a group of individuals recognizable as being biologically different from others.

It may be inferred from these definitions that the traits displayed by a given breed should be sufficiently well-defined and homogeneous within a group to enable them to be distinguished from those of any other group. Here, morphometric analysis was used to evaluate the homogeneity/ heterogeneity of the traits displayed by a given group of animals and to establish a gradient of distances between them.

Breed standards, and judging panels for morphological evaluation, are available for all the breeds and varieties studied here; this accounts for the high degree of selection already apparent; however, there is no breeding standard or judging panel for Orito, since it is not yet officially recognized as a breed.

The Podenco Ibicenco and the Podenco Canario have been subjected to more intense selective breeding pressure over a longer period, leading to greater morphometric homogeneity.

The Podenco Andaluz (all three sizes) was characterized much more recently (year 1992), and therefore selective breeding pressure has hitherto been less intense; this accounts for the greater variability observed. By the same token, studies aimed at characterizing the Orito hound are even more recent, so morphometric traits displayed the greatest variability of all the breeds studied; morphological breeding criteria have yet to be developed, and breeding to date has focused on hunting aptitude and coat color.

However, the behavior of the morphometric variables for the Orito hound was the most homogeneous of all the breeds studied; in both sexes, the same significant variables were found for Factors 1 and 2, indicating that the same general morphostructural traits applied in males and females.

In general terms, Factor 1 revealed that variations concerned body length and width, and chest and shin circumference, whilst Factor 2 concerned mainly rump width and head width.

This analysis is of immediate use in defining breeding criteria, since it identifies the overall variation of a group of linked variables, making it a useful tool for breed judges, whose job it is - in theory - to define selection criteria with a view to increasing the amount of variation explained by a single factor, since this will contribute to greater homogeneity among animals belonging to the same breed.

The method used here successfully differentiated between breeds; this is particularly important since the study sought to establish the extent to which the recently characterized Orito hound differs from other breeds. The morphometric traits of Orito females differed significantly from those of other breeds, as shown by the Euclidian distances recorded. Orito males were distinguished from all other breeds except the small Podenco Andaluz, although this result may have been masked by the small sample size involved.

Morphometric research in a variety of species has confirmed that morphostructure is determined by breed and also by breed aptitude (Herrera et al.; Macciotta et al.; Rodero et al.; Zaitoun et al.). Since each of the Podenco breeds has specialized hunting aptitudes, it is important to distinguish among breeds on the basis of morphometric traits, and also to ensure that individual animals are assigned to the right breed. Here, a close match of morphometric traits with aptitudes was observed; between $81.25 \%$ and $100 \%$ of animals were correctly classified, except for the small Podenco Andaluz, for which correct classification rates were lower.

Plotting of canonical coefficients confirmed that Podenco Orito may be considered a clearly differentiated population, a Podenco breed different from the other hitherto recognized breeds. The cluster trees indicated that this new breed is closer to the medium sized Podenco Andaluz, with which it shares both geographical location and hunting aptitudes.

In conclusion, the application of discriminate analysis to morphometric variables in dogs belonging to several Podenco breeds enabled breeds and varieties to be clearly distinguished, as reported for other species (Herrera et al.; Capote et al.; Crepaldi et al.; Macciotta et al.; Rodero et al.; Lanari et al.; Zaitoun et al.; Luque et al.; Dossa et al.; Marrube et al.; Vargas et al.; Traoré et al., 2008a; Traoré et al., 2008b).

The inclusion, in this analysis, of a new Podenco group, recently characterized and distinguishable from other Podenco breeds in terms of both morphology and color, enabled the new group (Podenco Orito) to be identified as a separate breed differing morphostructurally from other Podenco breeds and varieties. 
GONZÁLEZ, A.; LUQUE, M.; RODERO, E.; GONZÁLEZ, C.; AGUILERA, R.; JIMÉNEZ, J.; SEPÚLVEDA, N.; BRAVO, S. \& HERRERA, M. Uso de variables morfométricas para la diferenciación de razas de sabueso Español. Int. J. Morphol., 29(4):1248$1255,2011$.

RESUMEN: El término Podencos se refiere a un grupo de razas de perros originarios de España y clasificados en el grupo 5 de razas caninas por la Federación Cinológica Internacional (FCI). El objetivo del presente trabajo fue comparar caracteristicas morfométricas de las razas caninas de Podencos; Canario, Ibecenco, Andaluz (pequeño, medio y grande) y Orito. Se midieron diez variables morfométricas en 385 animales (245 hembras y 140 machos); longitud de la cabeza, la longitud hocico, altura a la cruz, alzada a la grupa, la longitud del cuerpo, ancho de la cabeza, ancho de la grupa, la profundidad del pecho, la circunferencia del pecho y la circunferencia de la caña. Las variables morfoestructurales fueron más homogéneas en el Podenco Ibicenco y el Podenco Canario, porque por muchos años fueron fijados gradualmente los rasgos distintivos para los estandares de cada raza. El análisis discriminante manifestó diferencias morfoestructurales entre todas las razas, lo que se refleja en la significativa distancia de Mahalanobis, y confirmó que el podenco Orito puede ser aceptado como una población de perros diferentes.

PALABRAS CLAVE: Morfometría; Razas de perros; Sabuesos; Multivariantes.

\section{REFERENCES}

Capote, J.; Delgado, J. V.; Fresno, M.; Camacho, M. E. \& Molina, A. Morphological variability in the Canary goat population. Small Rumin. Res., 27(2):162-7, 1998.

Cavalli-Sforza, L. Genes, Pueblos y Lenguas. Barcelona, Ed. Crítica, 2000.

Crepaldi, P.; Negrini, R.; Milanesi, E.; Gorni, C.; Cicogna, M. \& Ajmone-Marsan, P. Diversity in five goat populations of the Lombardy Alps: Comparison of estimates obtained from morphometric traits and molecular markers. J. Anim. Breed. Genet., 118(3):173-80, 2001.

Dossa, L. H.; Wollny, C. \& Gauly, M. Spatial variation in goats populations from Benin as revealed by multivariate analysis of morphological traits. Small Rumin. Res., 73(1):150-9, 2007.

Herrera, M.; Rodero. E.; Gutierrez, M. J.; Peña, F. \& Rodero, J. M. Application of multifactorial discriminant analysis in the morphostructural differentiation of Andalusian caprine breeds. Small Rumin. Res., 22(1):39-47, 1996.

Lanari, M. R.; Taddeo, H.; Domingo, E.; Pérez, M. \& Gallo, L. Phenotypic differentiation of exterior traits in local Criollo Goat Population in Patagonia (Argentina). Arch. Tierz., 46(4):34756, 2003.

Luque, M.; Rodero, E.; Peña, F.; García, A. \& Herrara, M. Application of discriminant analysis to the morphostructural differentiation of 7 extensive goat breeds. Annual meeting of the European Association for Animal Production. Uppsala, Sweden, 2005.

Macciotta, N. P. P.; Cappio-Borlino, A.; Steri, R.; Pulina, G. \& Brandano, P. Somatic variability of Sarda goat breed analysed by multivariate methods. Livest. Prod. Sci., 75(1):51-8, 2002.

Marrube, G.; Cano, E.; Roldán, D.; Bidinost, F.; Abad, M.; Allain, D.; Vaiman, D.; Toaddeo, H. \& Poli, M. QTL affecting conformation traits in Angora goats. Small Rumin. Res., 71:25563, 2007.

Rodero, E.; Herrera, M.; Peña, F.; Molina, A.; Valera, M. \& Sepúlveda, N. Morpho-structural model for Florida and Payoya Spanish dairy goats in extensive (grazing) systems. Revista Científica-FCV-LUZ, 13(5):403-12, 2003.

Traoré, A.; Tamboura, H.; Kaboré.; Royo, L.; Fernández, I.; Álvarez, I.; Sangaré, M.; Bouchel, D.; Poivey, J.; Francois, D.; Toguyeni, A.; Sawadogo, L.; Goyache, F. Multivariate analyses on morphological traits of goat in Burkina Faso. Archiv. Tierzucht., 6:588-600, 2008a.

Traoré, A.; Tamboura, H.; Kaboré, A.; Royo, L.; Fernández, I.; Álvarez, I.; Sangaré, M.; Bouchel, D.; Poivey, J.; Francois, D.; Toguyeni, A.; Sawadogo, L.; Goyache, F. Multivariate characterization of morphological traits in Burkina Faso sheep. Small Rumin. Res., 80:62-7, 2008b.

Vargas, S.; Larbi, A. \& Sánchez, M. Analysis of size and conformation of native Creole goats breeds and crossbreds used in smallholder agrosilvopastoral systems in Puebla, Mexico. Trop. Anim. Health Prod., 39(4):279-86, 2007.

Zaitoun, I. S.; Tabbaa, M. J. \& Bdour, S. Differentiation of native goat breeds of Jordan on the basis of morphostructural characteristics. Small Rumin. Res., 56(1):173-82, 2005.

Correspondence to:

Dr. Néstor G. Sepúlveda Becker

Profesor Titular

P.O. Box 54-D

Fono 56-45-325458

Universidad de La Frontera

Temuco, CHILE

Email: nestor@ufro.cl

Received: 17-06-2011

Accepted: 23-09-2011 